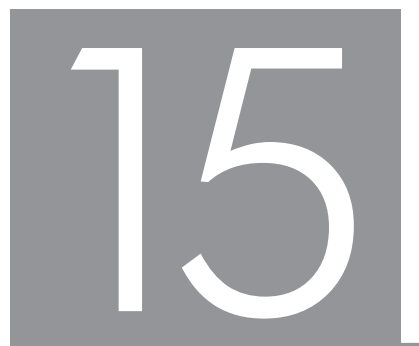

\title{
UNIVERSITIES AS ORGANISATIONS OR INSTITUTIONS?
}

\section{THE CULTURE DEBATE AND ONE INSTITUTION}

Berté van Wyk

\section{ABSTRACT}

This chapter attempts to conceptualise institutional culture by posing a critical question: Are universities institutions or organisations? The question arises due to ambiguities in the literature: several authors describe universities as institutions rather than organisations, while others use the notions of 'organisation' and 'institution' interchangeably. In agreement with Hoffman (1999) that it would be critically important to consider how and in what ways concepts of culture can enhance - or impede - understanding, research and action in education, I explore the culture debate. There seem to be complex conceptual issues associated with some of the baseline debates on the nature of culture and, following from this, the nature of institutional cultures. The literature suggests that institutional culture as a social construct is embedded in a very definite historical context and purpose (Louw and Finchilescu 2003), and this historical context becomes very useful in an analysis of what constitutes institutional culture at Stellenbosch University. The discussion on two meanings of institutional culture (perceptions, and the language issue) indicates that culture is dynamic, and highlights how meanings change over time. The essay suggests that there is no easy definition of 'institutional culture', as there is no one single characteristic of an institution that can be cited to define this culture. I conclude that the usefulness of institutional culture is that it connects people and should be used for a purpose; it is not just something to have, which is where the discussion of the concept usually focuses (Toma, Dubrow and Hartley 2005).

\section{INTRODUCTION}

Whenever I visit the university campuses of Stellenbosch, Cape Town and the Western Cape, I get an almost intuitive sense of the uniqueness of each of these three 


\section{PART FIVE - STRUCTURES AND GOVERNANCE}

institutions, but also of the differences between them. It has prompted me to reflect on what makes these institutions different from each other: is it the buildings (they certainly have different architectural styles), the students, the staff or the programmes? Or is it something else? I have come to realise that it is a complex task to explain what makes each of these institutions unique or different, keeping in mind that they are located not far apart geographically. Put differently, it appears at surface level that there is a (cultural) difference between institutions, but it is very complex task to describe such differences.

I find Harold Silver's (2003:157) question: "Does a university have a culture?" a good starting point for this discussion. He argues that "organisational culture" (that is, a culture applied to higher education institutions) has no basis in the day-to-day operation of most academic staff in most institutions. My contention is that while academics may not pay much attention to the culture of their institutions in their dayto-day activities, there is an inescapable, pervasive culture that determines how things are done at each institution.

However, due to the assumption that universities are organisations, Silver's use of the term 'organisational culture' with respect to universities is not unproblematic. I hold that, while it is true that institutions such as universities are pressurised to function increasingly as organisations, and (non-university) organisations tend to adopt a university culture, we should be careful not to conflate the two concepts. There is evidently an encroachment of organisational or corporate culture on the university in the form of managerialism, hence the difficulty to distinguish conceptually between institutions and organisations. I suggest a distinction between these two concepts, and will discuss that later.

This inquiry notes that the concept of institutional culture has not been sufficiently studied and that more research is needed. Two official documents share this view. The Council on Higher Education (CHE 1999:25) concludes that the extent to which institutions have developed institutional cultures is difficult to gauge, since no data on institutional culture has been gathered in any systematic way at either an institutional or a national level. The Ministry of Education (2001:46) emphasises that an important strategy that institutions have largely ignored is the need to change institutional cultures, and it highlights several points worthy of consideration. Firstly, the Ministry suggests that there is a need for refocusing institutional cultures nationally. I agree, as this is important for consolidating democracy and ensuring a unified national system of higher education, geared towards meeting the challenges of a democratic society. Secondly, institutions 
have largely ignored the need to change their institutional cultures. This may impact on the capacity of institutions to transform their cultures. Thirdly, institutional cultures can be either alienating or accommodating. Certainly this can be related to how institutions deal with diversity. The question is therefore how the institutional culture deals with such challenges. Since these pronouncements were made, institutional culture has received more attention and has become a topic for master's and doctoral research. In this regard Higgins (2007) observes that institutional culture has become a buzzword in recent discussions of higher education in South Africa. He points out the growing sense that institutional culture may well be the key to the successful transformation of higher education in South Africa. Similarly, Jansen (2004:1) observed: "[T] he last frontier in the quest for social integration and non-racial communities in former white institutions will always be this hard-to define phenomenon called 'institutional culture.'" This interpretation of institutional culture may account for the apparent lack of research data on the concept.

The merging of institutions also added to the complexity in describing the concept of institutional culture. The CHE (2004:54) briefly refers to this issue and identifies incompatible institutional cultures as possible consequences of institutional restructuring. I contend that institutional cultures resulting from mergers are hard to describe, since such institutions grapple with multiple factors in their re-organisation. This is a complicating factor in the study of institutional culture. In an attempt to further understand institutional culture in higher education institutions (universities), I next provide a conceptual exploration of the concept. This conceptualising assumes that a university (as an institution) does have a culture.

\section{CONCEPTUALISING INSTITUTIONAL CULTURE}

In an attempt to explore possible meanings of institutional culture I draw on the resources of philosophy. Here I agree with Wittgenstein (in Barnett 1992:1897) who states: "Through a searching analysis of the key concepts and terms that permeate the language of higher education, philosophy can help to clarify our thinking about the beliefs, presuppositions, and values on which higher education as a social practice is founded." An analysis of key concepts associated with the notion of an institutional culture may therefore assist with this inquiry; it follows that an exploration of institutional culture may be assisted by exploring the nature of institutions, the concept of culture, and discourses pertaining to institutional culture. I start this conceptualisation by posing a critical question. 


\section{PART FIVE - STRUCTURES AND GOVERNANCE}

\section{Are universities institutions or organisations?}

Before I continue with a discussion of the concept of culture, I want to touch briefly on the concept of institution, and I want to consider the above critical question which points to ambiguities in the literature. Several authors describe universities as institutions rather than organisations (see Kulati and Moja 2002; Neave 2001; Scott 2000; Chomsky 2003; Becker and Kogan 1992; Välimaa 1998) and I share this view. But there are also others (Toma et al. 2005; Thaver 2006) who use the notions of 'organisation' and 'institution' interchangeably in their discussions of universities. (They then refer to "organisational culture" and "institutional culture".) I find this problematic, as it assumes that organisations and institutions are similar. As far as institutions are concerned I share the view that an institution is not a place: it is a system, and a system functions - whatever its degree of coherence and integrity - as a de facto community. Thus, the community shapes the institutional character.

Tierney (in Higgins 2007) was one of the first scholars to propose the extension of the concept 'organisational culture' to cover the work and running of universities as organisations. The introduction of 'organisational culture' into higher education can be viewed as an encroachment of organisational or corporate culture on the university in the form of managerialism, and points to the blurring of the organisational and institutional roles of universities. This blurring of roles has impacted on the special role of the university as an institution dedicated to the pursuit of significant knowledge and lasting values.

I can understand the conflation of 'organisation' and 'institution', because universities, by nature of their institutional mandate, have to organise themselves in specific ways, and such organisation has a bearing on the way they conduct their affairs. Over the past few decades we have seen a change of higher education from a social institution to an industry; universities had to find innovative ways to deal with decreased state funding. As a result they had to become more competitive in order to boost student numbers, to attract the best staff and to conduct market-related research. These realities forced universities to pay more attention to the way they organise themselves, and in the process their institutional and organisational character became intertwined. It is not the intention to analyse the concepts of 'organisation' and 'institution' in greater depth, but these concepts are important in an inquiry of institutional culture, and for that matter, the role of culture in the ways universities are organised. 


\section{The culture debate}

My argument in exploring this concept is that a deeper understanding of culture can be very useful in an exploration of institutional culture. Hoffman (1999:465) suggests that it would be critically important to consider how and in what ways concepts of culture can enhance - or impede - understanding, research and action in education. But culture seems to be a very difficult concept to work with, and Välimaa (1998) cautions that culture is difficult to use as an instrument of research, because it can be defined in far too many ways. He adds that culture may also be problematic as a general framework of analysis, because it has to include as many elements of higher education institutions as possible (ecological characteristics, historical events, and institutional traditions and missions). Bauman (1999) explores culture as concept, as structure, and as praxis, and his analysis can be beneficial for this inquiry. Parekh (2000) provides further insights into understanding culture when he discusses the following aspects thereof: nature and structure, dynamics, cultural community, loyalty to culture, cultural interaction, cultural diversity, and evaluating cultures. Culture has also been described as ubiquitous (WASC 2001). This implies that every organisation, every department and even every little informal work team has a culture and that people are constantly surrounded by culture, which shapes their behaviour. Culture makes its presence known whenever a new leader appears or there is a change in managerial style. The fact that an institution has a culture implies that institutions are living and changeable entities, as are the people who comprise them. These brief references suggest that culture is a very difficult concept to work with, and that the concept lends itself to a variety of interpretations. Culture thus takes on many different meanings and directions, and that makes it difficult to explore institutional culture.

Since this essay explores institutional culture in higher education, I want to explore a conceptual link between higher education and culture. Barnett (1990) addresses this question when he explains how this culture works on two distinct levels. Firstly, the idea of culture has application in relation to the academic community. Secondly, culture manifests at the level of the process of higher education itself, the level which comes close to that of the student experience. Here the idea of culture suggests a shared set of meanings, beliefs, understandings and ideas - in short, a taken for granted way of life in which there is a reasonably clear difference between those on the inside and those on the outside of the community. There is value for society in the culture of higher education. Barnett's (1990) view is that the value does not lie in the acquisition of specific competencies, but that it is in direct proportion to the critical capacities of its students. 


\section{PART FIVE - STRUCTURES AND GOVERNANCE}

When exploring the concept of culture, there are both old and new ideas that can be considered. Wright (1998) mentions that according to the old views, culture is: bounded and a small-scale entity; defined characteristics (checklist); unchanging, in balanced equilibrium or self-producing; an underlying system of shared meanings: 'authentic culture'; identical, homogeneous individuals. Some new ideas are the following:

- Culture is an active process of meaning making and contestation over definition, including of itself.

- People differently situated in social relations and processes of domination use economic and institutional resources available to them to try and make their definition of a situation 'stick', to prevent others' definitions from being heard, and to garner the material outcomes.

- Sites are not bounded - people draw on local, national and global links.

- The way clusters of concepts form is historically specific, and ideas never form a closed or coherent whole.

- In its hegemonic form, culture appears coherent, systematic, consensual, like an object, beyond human agency, not ideological - like the old idea of culture. New ideas of culture seem to be more relevant for this inquiry.

Sackman et al. (1997:25) add to the debate when they suggest that the core of culture is composed of explicit and tacit assumptions or understandings commonly held by a group of people; that a particular configuration of assumptions and understandings is distinctive to the group; that these assumptions and understandings serve as guides to acceptable and unacceptable perceptions, thoughts, feelings and behaviours; that they are learned and passed on to new members of the group through social interaction; and that culture is dynamic - it changes over time, although the tacit assumptions that are the core of culture are most resistant to change.

In my view, there seem to be complex conceptual issues associated with some of the baseline debates on the nature of culture and, following from this, the nature of institutional cultures. For instance, one may ask: Is culture something that higher education institutions 'have', or are institutions themselves artefacts of culture? I contend that the relationships between social practices within institutions and the larger structural currents of society (as highlighted by Tierney 1988) must be considered to some extent in order to clarify assumptions about the extent to which social practices (and institutional cultures) influence the way universities are managed. 


\section{Institutional culture and higher education}

After having considered the nature of universities (institutional and organisational) and having explored the role of culture, I now come to a discussion of institutional culture. The latter is used widely in describing the personality of institutions. Toma, Dubrow and Hartley (2005) build on work on institutional culture of Tierney (1988), Kuh and Whitt (1988) and Schein (1992) and describe institutional culture as the shared beliefs, values, assumptions, and ideologies that bind a group together. They posit that institutional culture has subjective dimensions (e.g. shared assumptions, values, meanings and understandings) and also more objective aspects (physical artifacts, organisational stories, heroes and heroines, rituals and ceremonies), the former being less apparent than the symbols, language, narratives, and practices needed for conveying them.

Kuh and Whitt (1988), who also contend that culture is a difficult concept to work with, suggest that a study of institutional culture is, however, not unproblematic, because the concept of culture as a general framework of analysis has to include as many elements of higher education institutions as possible (ecological characteristics, historical events and institutional traditions and missions). Lee (2004) emphasises this point by concluding that a study of institutional culture must acknowledge the heterogeneity of values, beliefs, and priorities across, for instance, the independent academic departments. Thus, one cannot assume that people attached to an institution have a uniform understanding or meaning of institutional culture. In my view, a study of the theme has to acknowledge that institutional culture as a social construct is embedded in a very definite historical context and purpose (Louw and Finchilescu 2003), and is usually taken for granted and continues to be played out in an 'invisible manner' (Steyn and Van Zyl 2001).

When speaking about institutional culture, one can also consider academic or university culture as a key aspect. According to Mora (2001:95), university culture can be regarded as the beliefs of the members of the university community developed over centuries and transmitted through both language and symbols. He states that university culture is decisive in determining the behaviour of members of the university community and in the governance and decision-making processes of the institutions themselves. He further suggests that it is often unspoken common assumptions that best explain the behaviour of members of the academic world. Since academic culture is evident in the way that academic departments are organised, my observation is that departments organise themselves very differently as a result of those who shape the ideas and practice within a distinct community. Thus, an institution consists of many 


\section{PART FIVE • STRUCTURES AND GOVERNANCE}

(and a variety of) institutional cultures. But let me also add that there is very often a dominant view or group that articulates the common and/or shared meanings.

To make sense of "unspoken common assumptions" can be a very difficult exercise. This difficulty is eloquently articulated by Fay (1996:115):

The interpretation of the meanings of actions, practices and cultural objects is an extremely difficult and complicated enterprise. The basic reason for this is that the meaning of something depends upon the role it has in the system of which it is a part, and this system may be exceedingly complex and rich. In order to know the meaning of certain overt movements interpreters must understand the beliefs, desires, and intentions of the particular people involved. But in order to understand these, they must know the vocabulary in terms of which they are expressed, and this in turn requires that they know the social rules and conventions which specify what a certain movement or object counts as. Moreover, in order to grasp these particular rules, they also have to know the set of institutional practices of which they are a part, and how these relate to other practices of the society.

Drawing on the nature of universities, I suggest institutional culture should also imply that institutions establish a stable structure for human interaction, and construct forms of consciousness. Since culture is composed of explicit and tacit assumptions or understandings commonly held by a group of people, and its core is resistant to change, such resistance could explain why universities, in their efforts to transform, have largely ignored transforming institutional cultures. A complicating factor could be that cultures in universities are multiple, and that they are generated at the level of the workgroup within departments; and in order to address the issue of culture it may be necessary to go down to this level (Trowler 2008:15). There are also many aspects pertaining to universities (environment, mission, socialisation, information, strategy, leadership, management, institutional practices, institutional traditions, language, symbols, institutional priorities, national and local policies and procedures) which may influence institutional culture. I shall refer to some of these in the next section.

\section{STELLENBOSCH UNIVERSITY: A CASE STUDY OF INSTITUTIONAL CULTURE}

Since the Higher Education Quality Committee (HEQC 2007:14) recommended that "Stellenbosch University develop a comprehensive strategy to transform its institutional culture" there has been a renewed debate on campus. The following aspects are under discussion: disillusionment and estrangement, embracing of new ideas, how to deal with difference, perceptions of the university, race and ethnicity, religious beliefs, sexual orientation, the role of language, and the idea of a secular culture. 
An underlying idea in the debate is how to create a home for all at the university. The debate is very useful in that it provides an opportunity for a critical engagement on the culture of the institution. However, I find that these debates do not pay attention to the question whether universities are institutions and/or organisations. Consideration of this question could add a critical dimension to the debate.

At a policy level, the university makes various pronouncements on institutional culture in its documents, and I find the Concept 2 Diversity Framework (University of Stellenbosch 2003) perhaps the most useful in its articulation of the theme. The document identifies and discusses the following meanings of institutional culture within the context of diversity: values and codes of conduct, perceptions, physical symbols, language, ceremonies, university structures and bodies, corporative facilities, and sport.

These meanings, as articulated by the university, provide a very neat description of what the university regards as constitutive of its institutional culture. Although I would have liked to analyse all of these, for purposes of this inquiry I shall touch briefly on only two meanings which seem to be quite prominent in the news and debates, namely the 'language issue' and 'perceptions'.

\section{The language issue}

Undoubtedly, language is a very important and controversial current issue of Stellenbosch University (SU), and there are many opinions on it. The university acknowledges that for most of its existence the ethnic exclusivity of the institution was guaranteed and reinforced by the fact that it adopted Afrikaans as a medium of instruction. With the repositioning of the institution a language policy was designed in 2002 and Afrikaans was identified as the default institutional language of choice for academic and communication purposes. While the policy acknowledges the special status of Afrikaans which must be promoted, it accords such privileged status in terms of a multilingual context. This position, understandably, has been received both positively and negatively by different internal and external constituencies. The positive dimension of the language policy is often raised, although not exclusively, by those whose mother tongue is Afrikaans and those who are reasonably proficient in Afrikaans and English. The negativity with regard to Afrikaans, while it does criticise the language in terms of it being a tool for communication, is perhaps due to the fact that Afrikaans is being elevated to an institutional 'core value', alongside equity, diversity and scholarship.

The importance of language is shown by research findings of the Department of Journalism (2005) on Stellenbosch University as a topic of readers' letters in the 


\section{PART FIVE • STRUCTURES AND GOVERNANCE}

newspaper Die Burger (2002-2005). During the period 13 May to 28 October 2002, $14 \%$ (137 out of 957) of all the letters published had SU as subject. Altogether $83 \%$ (1 14 out of 137) of the SU letters focused on the theme Language Policy.

In interviews conducted with relevant editorial staff from Die Burger (Department of Journalism 2005:17,18) the following views are expressed:

Like all other higher education institutions, $\mathrm{SU}$ is going through a process of transformation. Against this background, transformation at $\mathrm{SU}$ is something that we will always approach as a news item: how it is approached, the critique around it, where the university is heading, the future of the university. Connected to that is the emotive component of Afrikaans. One of the products of the transformation process is that Afrikaans as a language at the university is endangered. People talk about it. The public's involvement at SU and the Afrikaans language a combination of these two factors makes it newsworthy. It is not happening on the same scale at other universities.

We see SU as a breeding ground for Afrikaans, and it will always be, and it must always be so. But that does not mean that - within the greater institution that gives a platform for Afrikaans academics to publish and lecture in Afrikaans, etc. - it should be a narrow-minded institution that has to function within the greater South Africa and international academic circles ... We naturally see SU as an Afrikaans institution and we will focus on that. To us it is important that it should remain that, even if it becomes the only one in the country that has that status at a tertiary level.

Stellenbosch University positions itself as a language-friendly university, with a responsive and flexible approach to language of instruction, and with Afrikaans as its point of departure (University of Stellenbosch 2000). In its Concept 2 Diversity Framework (2003) the university acknowledges that its language policy necessarily impacts on the development of diversity. There have been many debates at the university about the impact of its language policy, which have been articulated by students as the advancement of Afrikaans as the basic teaching and institutional language of the SU, within a multilingual context. Consequently, the university has failed to attract large numbers of black students (who prefer English as medium of instruction). I have been part of numerous discussions on the medium of instruction, and have listened to many views in support of Afrikaans. But I do get the impression that it is not as simple as that - it is not just about language, it is also about the ideology in which discussions on language is embedded.

The ideology, and history, of the language debate is articulated by Prof Chris Brink (2005a), former Rector of Stellenbosch University, as follows: 
Stellenbosch was one of the main intellectual sources of apartheid ... the association of the University with the power structures of Afrikanerdom was, for a long time, a close one. DF Malan, the first apartheid Prime Minister, was a Stellenbosch man. Hendrik Verwoerd was a Professor of Sociology and Social Work here before turning to politics. John Vorster was a prominent student leader who later, as Prime Minister, became Chancellor of the University. The last apartheid President, PW Botha, likewise became Chancellor at the time of his political power (even though he had no previous connection with the University). Rectors of the University were typically prominent members of the Afrikaner Broederbond.

My observation is that language at Stellenbosch University accounts for a major part of its institutional culture, and this impacts negatively on its student and staff profile. For instance, contrary to national trends where South African university profiles are becoming increasingly more diverse, with a concomitant drop in white students, the white student profile at Stellenbosch has remained unusually high and steady (2005:71.55\%; 2006:71.59\%; 2007:70.51\%; 2008:68.6\%). To emphasise the importance of language, there were renewed debates on the issue in May 2009, and the University Council (2009:2) responded by stating that "in 2010, parallelmedium instruction will be presented in the first year of study in four faculties - Science, Engineering, Agrisciences and Economic and Management Sciences ... Management will facilitate further consultation and discussion within the framework of the Language Policy and Plan, specifically on the teaching language model for the senior years of study as of $2011 . "$

To conclude this section: I have also heard colleagues openly arguing for substantial change in the language policy, and calling for a change to English as the medium of instruction. It is not such a far-fetched idea, as many of our students who graduate as teachers in the Faculty of Education (where over $90 \%$ of students at undergraduate level are white) prefer to teach in the United Kingdom, where they teach in English. The option of parallel-medium instruction also presents considerable challenges. Moreover, one has to consider whether there are enough Afrikaans-speaking students to ensure the sustainability of the university. What cannot be denied, though, is that language carries institutional meanings, and an Afrikaans medium of instruction might exclude African students from gaining access to the institution.

\section{Perceptions}

Despite efforts of the university to change perceptions, there is still a perception that Stellenbosch University is largely white-, male-, Afrikaans-, and Christian-dominated, 


\section{PART FIVE - STRUCTURES AND GOVERNANCE}

and conservative. These perceptions are reinforced by the language of policy documents of the institution. Despite a national focus on transformation, my scrutiny of the Strategic Framework of the university (2000) has revealed a total absence of the concept of transformation. Concepts such as 'positioning', 'changing', 'reposition', 'redesign', 'self-renewal', 'self-scrutiny', 'reassessment' are prevalent in the text, but 'transformation' does not appear even once. What does this mean? Two seminal government policy documents (Education White Paper 3 and the National Plan for Higher Education) revolve largely around the concept 'transformation' and meanings which underscore its manifestation in higher education. Given the historical and political background of Stellenbosch University, there seems to be a subtle reluctance to use the concept. My inference is that it seems as if the notion of transformation as articulated in some government policy documents might not necessarily be commensurate with the institution's 'positioning' in terms of the changes which currently transpire in higher education - hence the perception that the university is lagging behind on transformation.

Let me illustrate my point. On 27 July 2005 a former rector and vice-chancellor, Professor Chris Brink (2005b) delivered a speech entitled "Annual Public Report by the Rector on transformation and Quality at Stellenbosch University". I find the title of his speech very striking. Transformation is spelt with a lower case ' $t$ ' and quality with a capital ' $Q$ '. I can only assume that this is a very deliberate formulation. If my assumption is correct, then the message is conveyed that transformation at Stellenbosch is not so high on the agenda, but quality certainly is. Such incidents confirm, rather than negate, perceptions about the institution.

Brink (2005b:3) further enforced perceptions of the institution when he stated that amongst many of the institution's traditional constituency, as manifested by Group 2 in the university's CREST (Centre for Research and Science and Technology) Report, there is a recurrent fear that transformation will erode quality. He also stated that many Afrikaner alumni are of the view that Stellenbosch was always an outstanding university, but that it is now sadly in decline, or at least in imminent danger of decline, because of transformation. Professor Brink made two striking observations. The first is that during the long time of Afrikaner political dominance, Stellenbosch had no need to measure its own quality other than by its own yardstick. Inevitably, this led to an unsubstantiated self-image of overall excellence. Secondly, in terms of all the usual measurable parameters, academic quality at Stellenbosch has slowly but surely been increasing at the same time as the university started opening up to the outside world. 
I will now attempt to explore the self-image which Brink talks about. The first postapartheid Minister of Education (Professor Sibusiso Bengu) issued a communiqué in 1995 to all South African higher education institutions to encourage them to establish Transformation Forums (TFs); at the same time he expressed an unwillingness to interfere in institutional management and to resolve disputes between TFs and other structures of governance, or to accede to the demands of student organisations. While two neighbouring universities (the University of Cape Town and the University of the Western Cape) heeded the call to establish TFs, Stellenbosch completely ignored it. Later, however, the Higher Education Act 101 of 1997 legislated for the establishment of four higher education governance structures: Council, Senate, SRC and Institutional Forum (IF). Stellenbosch was then forced to establish an IF without having had the experience of a TF; and managed to establish the IF in September of 1999, thereby meeting the deadline. It is interesting to note also that only Stellenbosch has decided upon a perfect balance across all four categories of representation (government and management, staff, students, and other community-based representatives). Harper et al. (2002) provide a possible explanation when they conclude that many institutions have tended to give preference to the letter of the Act, while ignoring the transformational purpose of the IF in earlier policy documents.

Perceptions about the university are further articulated by CREST (2005:vii) which also conducted an investigation into the "SU Trademark". They tested current students on the pace of change at SU, and these are the key findings:

- White Afrikaans-speaking students are largely divided over transformation at SU. Similar proportions believe that transformation is being handled responsibly or somewhat irresponsibly.

- White non-Afrikaans-speaking students also fall into two groups - one group that feels that transformation is being conducted in a responsible manner (47\%), and a second group that feels that the rate of transformation is unsatisfactory (42\%). Interestingly, this profile is very similar for black, coloured and Indian Afrikaans speaking students.

- The largest percentage of black, coloured, Indian and non-Afrikaans-speaking students (60\%) does not believe that SU is being adequately transformed. There is, however, also a large percentage (36\%) of this sub-group who believes that $\mathrm{SU}$ is not only being transformed, but that this is also being done in a responsible manner. 


\section{PART FIVE - STRUCTURES AND GOVERNANCE}

This discussion on perceptions shows that, despite exemplary institutional plans, Stellenbosch has failed to change negative perceptions about the institution. It also highlights that there is still a great challenge for the institution to free itself from the historical and ideological burdens of the past. These perceptions cannot be ignored, as they impact on the ability of the institution to function effectively in a democratic society. It is encouraging to note that the current (2009) Rector, Professor Russel Botman, talks more readily about transformation, and boldly addresses the perception of people from previously disadvantaged communities who indicate that race and ethnicity should be important considerations in discussions on institutional culture. The Overarching Strategic Plan (OSP) of 2009, which seeks to promote democracy and to maintain and promote human dignity, has the potential to change perceptions of the university.

\section{CONCLUDING REMARKS}

This inquiry assumes that a university (as an institution) has a culture, and I have argued that a deeper understanding of the concept of culture is very useful in an exploration of institutional culture. I have pointed out that there are complex issues associated with debates on culture, and following from this, the nature of institutional culture. My exploration indicates that there is, however, no easy definition of 'institutional culture', as there is no one single characteristic of an institution that can be cited to define this culture. It also acknowledges that an institutional culture does not develop overnight (WASC 2001). I support the view that a strong institutional culture has concrete uses in universities and colleges, and that culture is not simply something that is, but is something that can do. The usefulness of institutional culture is that it connects people, and is not just something to have, which is where the discussion of the concept usually focuses, but that it is something to use (Toma et al. 2005). Human interaction should thus be an important feature of an institutional culture, and attention should be paid to how the institutional culture facilitates diverse groups to interact with each other. An exploration of institutional culture in higher education also assists us in organising ourselves, as institutional culture does the following (Toma et al. 2005:6): it conveys a sense of identity (who we are), facilitates commitment (what we stand for), enhances stability (how we do things around here), guides sense-making (how we understand events), and defines authority (who is influential).

Currently, many universities in South Africa are attempting to construct a new and shared institutional culture. This might require that institutional culture be deconstructed in order to reconstruct a new culture, and one has to be mindful that an institution 
consists of many and a variety of institutional cultures. The reconstruction of (new) culture(s) is proving to be a major challenge.

Finally, some comments on possible future areas of research on the topic. Firstly, more research is needed on the institutional versus the organisational character of universities. This is a crucial area which seems to have been overlooked in the literature. Secondly, since this essay indicates that culture takes on many different meanings and directions, there is a need to explore how these meanings shape institutional culture at different levels (macro-, meso- and micro-levels). Thirdly, I suggest that we continue to explore institutional culture in relation to what Trowler (2008) refers to as educational ideologies: the aim of higher education (a liberal education or a vocational one), content (discipline-based propositional knowledge or general transferable skills), and the important functions taking place within it (research or teaching).

\section{REFERENCES}

Barnett R. 1990. The Idea of Higher Education. Buckingham, Bristol: SRHE \& Open University Press.

Barnett R. 1992. Philosophy. In: BR Clark \& G Neave (eds). The Encyclopedia of Higher Education. Vol. 3. Analytical Perspectives. Oxford, New York: Pergamon Press. 1896-1907.

Bauman Z. 1999. Culture as Praxis. London, Thousand Hills, New Delhi: Sage.

Becker T \& Kogan M. 1992. Process and Structure in Higher Education. 2nd Edition. London \& New York: Routledge.

Brink C. 2005a. On the juxtaposition of apparent opposites. Opening Address at the Workshop on Transdisciplinarity presented by the Sustainability Institute, Stellenbosch University. Stellenbosch. 11 April.

Brink C. 2005b. Annual public report by the rector on transformation and quality at Stellenbosch University. Stellenbosch. 27 July.

Centre for Research on Science and Technology (CREST). 2005. Investigation into the 'SU Trademark'. Stellenbosch: Crest.

CHE (Council on Higher Education). 1999. Annual Report 1998/99. Pretoria: CHE.

CHE (Council on Higher Education). 2004. South African Higher Education in the First Decade of Democracy. Pretoria: CHE.

Chomsky N. 2003. Chomsky on Democracy and Education. New York \& London: Routledge Falmer.

Council of Stellenbosch University. 2009. Communication from Council. Stellenbosch: Priority Bulletin. 4 May.

Department of Journalism. 2005. Stellenbosch University as a topic of readers' letters in the newspaper Die Burger (January 2002-March 2005). Stellenbosch University: Department of Journalism. 


\section{PART FIVE • STRUCTURES AND GOVERNANCE}

Fay B. 1996. Contemporary Philosophy of Social Science. Oxford, UK: Blackwell Publishers.

Harper A, Olivier N, Thobakgale S \& Tshwete Z. 2002. Institutional Forums: An Overview of their Establishment and Functioning at South African Public Higher Education Institutions. Pretoria: Centre for Higher Education Transformation (CHET).

HEQC (Higher Education Quality Committee). 2007. Audit Report on Stellenbosch University. Pretoria: CHE.

Higgins J. 2007. Institutional culture as keyword. In: Review of Higher Education in South Africa: Selected Themes. Pretoria: CHE. 97-114.

Hoffman DM. 1999. Culture and Comparative Education: Toward Decentering and Recentering the Discourse. Comparative Education Review, 43(4):464-88.

Jansen J. 2004. How Far Have We Come? Mail \& Guardian, 13-19 August: 1 Getting Ahead Supplement.

Kuh GD \& Whitt EJ. 1988. The invisible tapestry: Culture in American colleges and universities. ASHE-ERIC Higher Education Reports. Washington, DC: Association for the Study of Higher Education.

Kulati T \& Moja T. 2002. Leadership. In: N Cloete, R Fehnel, P Maassen, T Moja, H Perold \& T Gibbon (eds). Transformation in Higher Education. Global Pressures and Local realities in South Africa. Lansdowne: Juta. 230-260.

Lee JJ. 2004. Comparing Institutional Relationships with Academic Departments: A Study of Five Academic Fields. Research in Higher Education, 45(6):603-623.

Louw J \& Finchilescu G. 2003. UCT organizational climate survey. Unpublished report. University of Cape Town.

Ministry of Education. 2001. National Plan for Higher Education. Pretoria: Ministry of Education.

Mora J-G. 2001. Governance and management in the new university. Tertiary Education and Management, 7:95-110.

Neave G. 2001. The European Dimension in Higher Education: An Excursion into the Modern Use of Historical Analogues. In: J Huisman, P Maassen \& G Neave (eds). Higher Education and the Nation State: The International Dimension of Higher Education. Oxford: Elsevier Science. 13-72.

Parekh B. 2000. Rethinking Multiculturalism. Cultural Diversity and Political Theory. Hampshire and London: Macmillan Press.

Sackman SA, Philips ME, Kleinberg MJ \& Boyacigiller NA. 1997. Single and Multiple Cultures in International Cross-Cultural Management Research: Overview. In: SA Sackman (ed). Cultural Complexity in Organizations. Inherent Contracts and Contradictions. Thousand Oaks: Sage Publications. 14-48.

Schein EH. 1992. The Corporate Culture. Sense and Nonsense about Cultural Change. San Francisco: Jossey-Bass.

Scott P. 2000. A Tale of Three Revolutions? Science, Society and the University. In: P Scott (ed). Higher Education Re-formed. London \& New York: Falmer Press. 190-206. 
Silver H. 2003. Does a University Have a Culture? Studies in Higher Education, 28(2):157-168.

Steyn M \& Van Zyl M. 2001. Like that statue at Jammie stairs. Students' perceptions and experiences of institutional culture at the University Cape Town. 1999. Institute for Intercultural and Diversity Studies of Southern Africa. Unpublished report. University of Cape Town.

Thaver L. 2006. "At home", institutional culture and higher education: Some methodological considerations. Perspectives in Education, 24(1):15-26.

Tierney WG. 1988. Organizational Culture in Higher Education: Defining the essentials. The Journal of Higher Education, 59(1):2-21

Toma JD, Dubrow G \& Hartley M. 2005. The uses of Institutional Culture. Strengthening Identification and Building Brand Equity in Higher Education. ASHE Higher Education Report, 31 (2). Wiley Periodicals, Inc.

Trowler P. 2008. Cultures and Change in Higher Education. New York: Palgrave Macmillan.

University of Stellenbosch. 2000. A Strategic Framework for the turn of the century and beyond. Final copy edited following the Council meeting of 20 March 2000, Stellenbosch.

University of Stellenbosch. 2003. Concept 2 Diversity Framework. Stellenbosch, 17 March.

Välimaa J. 1998. Culture and identity in higher education research. Higher Education, 36(2): $119-138$.

WASC (Western Association of Schools and Colleges) 2001. Institutional Culture. Self-Study for an Accreditation Review prepared by the WASC Committee, Department of Academic Affairs, California State University Pomona - Chapter 5 [Online]. Available: http://www. csupomona.edu/ wasc/archive/selfstudy/culture/index.html/ [2009, 23 January].

Wright S. 1998. The politicization of culture. Anthropology Today, 14(1):7-15. 